\title{
ELABORATION AND CHARACTERIZATION OF THE NANOMETRIC TITANIUM DIBORIDE POWDERS BY THE MECHANICAL MILLING METHOD
}

\author{
I. Stefan*, G. C. Benga, A. Olei \\ University of Craiova, Faculty of Mechanics, Romania \\ *Corresponding author's e-mail address: stefan_iuly@yahoo.com
}

\begin{abstract}
The research activities are oriented towards elaborating and characterizing nanosized powders by powder metallurgy technologies based on wet milling in a planetary mill. For the elaboration of the $\mathrm{TiB}_{2}$ powders, a wet milling regime of initial powders was used up to nano size with the following parameters: milling technology by collision, milling times, rotational speed. The characterization of the $\mathrm{TiB}_{2}$ material will include particle size distribution analysis. EDXS and SEM analysis were used to study the structural evolution of the powder after ball milling. The mechanical milling technology, by its milling regimes, proved to be very efficient, obtaining a reduction of the titanium diboride powders particle size up to $50 \%$ compared to the initial unmilled powders.
\end{abstract}

KEYWORDS: $\mathrm{TiB}_{2}$, mechanical milling, nanometric, particle size, powder

\section{INTRODUCTION}

$\mathrm{TiB}_{2}$ is well known as a ceramic material with hexagonal crystal structure and it has been widely used in various industrial and military applications due to its high melting temperature, hardness and thermal diffusivity, excellent refractory properties and chemical inertness [2], [6]-[8]. Titanium diboride is the most stable of the intermetallic compounds between the titanium (Ti) and boron (B) system [7].

Figure 1 shows the lattice parameters of $\mathrm{TiB}_{2}$ which have slightly quadratic dependence, and $\mathrm{a}=\mathrm{b}=302.9 \AA, \mathrm{c}=322.9 \AA, \alpha=\beta=90^{\circ}, \mathrm{g}=120^{\circ}$. The prevalent covalent bonding determines the low ductility, high hardness and high melting point [4].

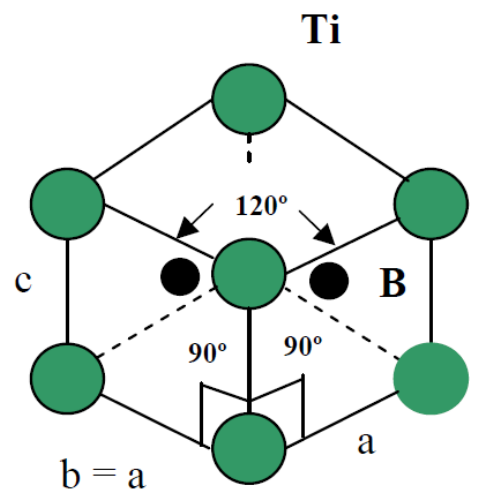

Fig. 1. The crystal structure of $\mathrm{TiB}_{2}[3]$, [4], [9]
There are different methods mentioned in the literature that may be used to obtain nanocrystalline materials. Several researchers have used the mechanical milling method to obtain a reduction of $\mathrm{TiB}_{2}$ powder particles [1], [5].

When comparing the energy-consuming reduction processes, one of the advantages of this method is that it is a simple method for producing nanocrystalline materials, at room temperature [8].

In the present study, a high-energy ball milling process, named mechanical milling, was used.

Titanium diboride powders, with a particle size of about 1 micron, were used in the present research. The aim was to reduce the powder particle size using a milling ratio of balls/powder and different milling times. The work technology by collision in the milling process was used.

The research conducted in this paper shows that the work technology by collision, the milling ratio and time significantly influence the reduction of $\mathrm{TiB}_{2}$ powder particle sizes.

These materials, developed in this paper, will be used in future studies, as armouring materials. It is necessary that their mechanical properties be high performance. It is known that the mechanical properties of $\mathrm{TiB}_{2}$ compound depend on grain size and become harder as the grain size decreases. The particle size of the $\mathrm{TiB}_{2}$ powders should be as small as possible so that, during sintering, the grain size shall not exceed 1 micron. 


\section{MATERIALS AND METHODS}

The raw materials used in this study were $\mathrm{TiB}_{2}$ commercial powders (purity $>99 \%$, Sigma-Aldrich). Raw materials were mechanically milled in a varioplanetary mill (FRITSCH - Pulverisette 4 type) in a wet medium (distilled water). Figure 2 shows the planetary mill parameters used for the research.

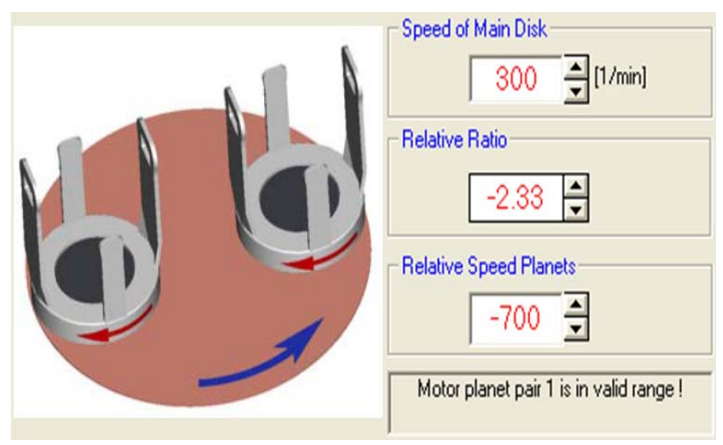

Fig. 2. Planetary mill parameters

Figure 2 shows that the speeds used for milling by collision are: the speed of the main disk $300 \mathrm{rpm}$ and the speed of the planets equal to $-700 \mathrm{rpm}$, respectively. The reason why the rotation direction of the planets is opposite to that of the main disk is that the authors chose to use the working technology by collision. The steel bowl was hardened steel of $250 \mathrm{ml}$ volume that was filled with 50 steel balls that were 10 $\mathrm{mm}$ in diameter. The experiments were carried out in a wet medium. A ball-to-powder mass ratio of 3:1 was used. The milling times were 0 hour, 2 hours and 3 hours in order to optimize the ball milling process and obtain the finest particles of titanium diboride. Time 0 means that the powders are in the initial state.

The size and particle size distribution of the milled powders were determined by the laser light scattering method, using a BROOKHAVEN 90 PLUS BI - MAS device. Energy-dispersive X-ray spectroscopy (EDXS) and scanning electron microscopy (SEM) were used to study the structural evolution of the $\mathrm{TiB}_{2}$ powder.

\section{RESULTS AND DISCUSSION}

The mechanical milling of the $\mathrm{TiB}_{2}$ powder particles is a process that takes place with great intensity and has visible effects, namely changing the size of powder particles. $\mathrm{TiB}_{2}$ powders were mechanically milled in a high energy ball mill in order to bring the powder particles as close as possible to the nanometric range. Both mechanically milled and unmilled powders were analyzed in order to determine the morphology. So, figures 3 and 4 show the particle size distribution and scanning electron microscopy SEM for the initial $\mathrm{TiB}_{2}$ powder and figure 5 shows the X-ray spectroscopy for these unmilled powders.

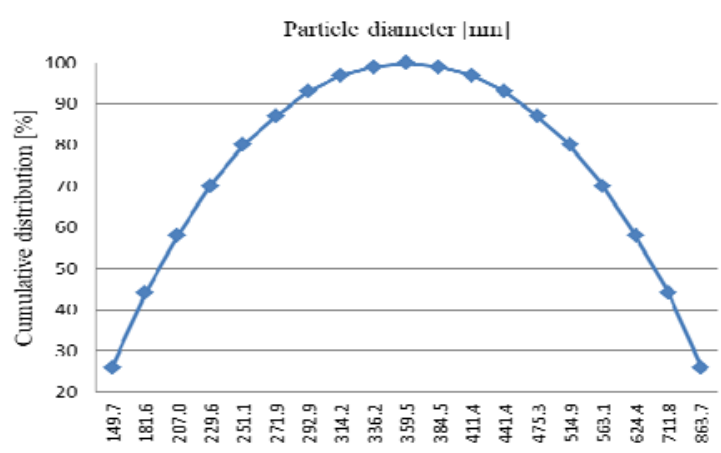

Fig. 3. Particle size distribution of the unmilled $\mathrm{TiB}_{2}$ powders

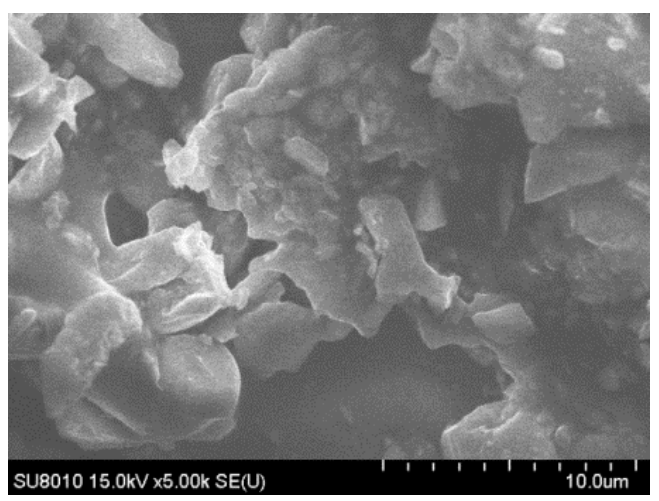

Fig. 4. SEM images of the unmilled $\mathrm{TiB}_{2}$ powders

The figures above show the shape of the $\mathrm{TiB}_{2}$ powder particles and the particle size range of the sample, namely [0.1-0.8 $\mu \mathrm{m}]$. It is also observed that there is a large volume of particles with a size of 0.35 $\mu \mathrm{m}$, but there are also two areas where the particles are smaller and larger than $0.35 \mu \mathrm{m}$, as seen in the SEM micrograph in figure 4.

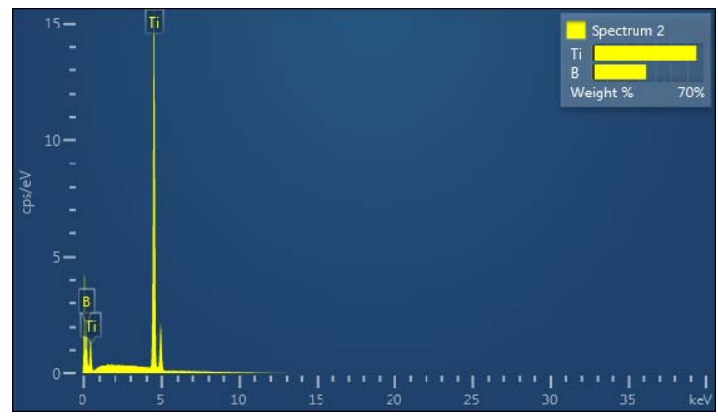

Fig. 5. X-ray spectroscopy of the unmilled $\mathrm{TiB}_{2}$ powders

The spectrum in figure 5 highlights the presence of the $\mathrm{Ti}$ and $\mathrm{B}$ elements in the form of the $\mathrm{TiB}_{2}$ compound.

Furthermore, figures 6 and 7 show the particle size distribution and scanning electron microscopy SEM for the $\mathrm{TiB}_{2}$ powders, milled for $2 \mathrm{~h}$. 


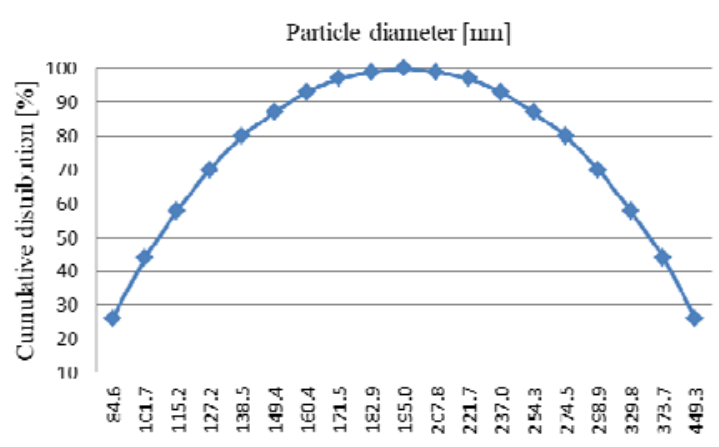

Fig. 6. Particle size distribution of the $\mathrm{TiB}_{2}$ powders milled for $2 \mathrm{~h}$

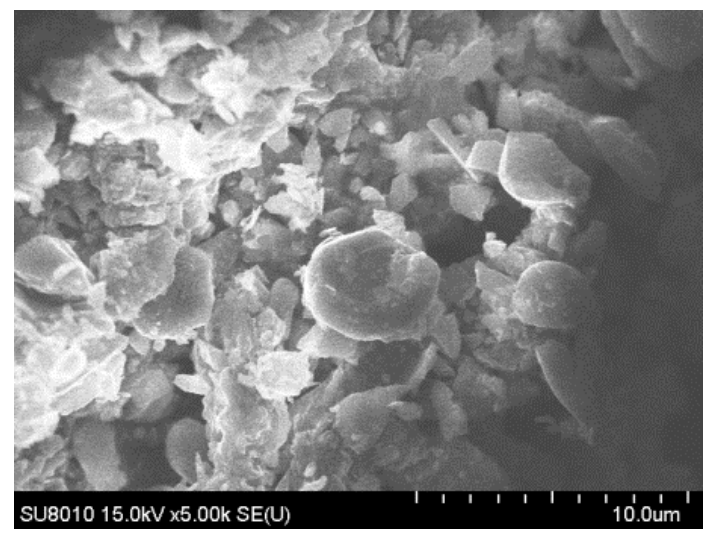

Fig. 7. SEM images of the $\mathrm{TiB}_{2}$ powders milled for $2 \mathrm{~h}$

After two hours of mechanical milling, a particle size range between [0.08-0.4 $\mu \mathrm{m}]$ was recorded. The large volume of particles is now situated at $0.19 \mu \mathrm{m}$ and it is observed that some particles are placed in the nanometric domain, more precisely at $84 \mathrm{~nm}$. The particles in the coarser area also decreased a lot, up to $0.44 \mu \mathrm{m}$. The SEM image shows this decrease in the particle size of titanium diboride powders and the hexagonal shape of the particles is better observed.

The last sample seen in figures 8 and 9 exhibits the particle size distribution for the $\mathrm{TiB}_{2}$ powders, milled for $3 \mathrm{~h}$, and the analysis by scanning electron microscopy (SEM).

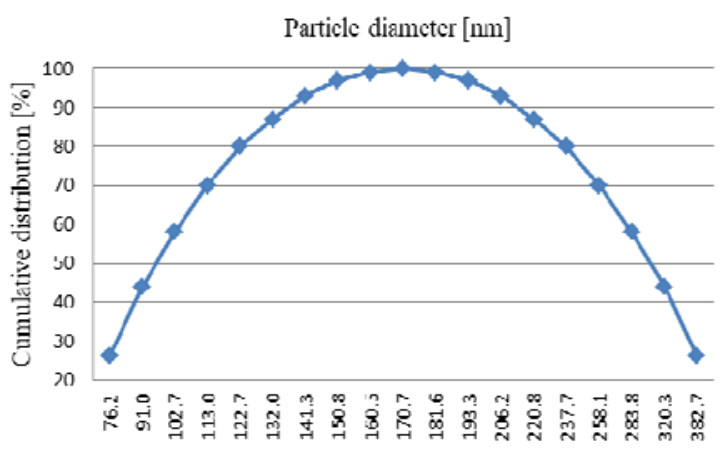

Fig. 8. Particle size distribution of the $\mathrm{TiB}_{2}$ powders milled for $3 \mathrm{~h}$

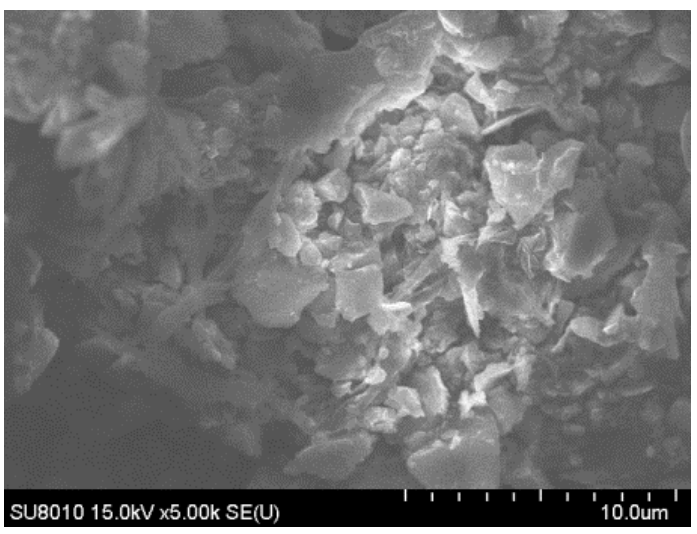

Fig. 9. SEM images of the $\mathrm{TiB}_{2}$ powders milled for $3 \mathrm{~h}$

A particle size range between [0.07-0.3 $\mu \mathrm{m}]$ was recorded for the final sample. The majority of $\mathrm{TiB}_{2}$ particles decreased up to $0.17 \mu \mathrm{m}$. With the increase of the mechanical milling time up to $3 \mathrm{~h}$, several nanometric particles of titanium diboride appeared. However, the size of the powder particles did not decrease too much compared to the sample milled for 2 hours. This happened mainly because the very small powder particles were agglomerated, as it can be seen in the SEM image in figure 9.

\section{CONCLUSIONS}

In this paper, the research activities were carried out in order to develop materials based on titanium diboride powders, with dimensions as close as possible to the nano field, by the mechanical milling method.

The results of the experimental activities are shown in table 1, and allow for drawing the following conclusions:

Table 1. Results of experimental activities

\begin{tabular}{|c|l|c|c|}
\hline No. & Samples & $\begin{array}{c}\text { Particle } \\
\text { size ranges } \\
{[\boldsymbol{\mu} \mathbf{m}]}\end{array}$ & $\begin{array}{c}\text { Median } \\
\text { diameter } \\
{[\boldsymbol{\mu} \mathbf{m}]}\end{array}$ \\
\hline 1. & $\begin{array}{l}\text { TiB } 2 \text { unmilled } \\
\text { powders } \\
\text { TiB } 2 \text { powders } \\
\text { milled for } 2 \mathrm{~h} \\
\text { TiB } \\
\text { milled for } 3 \mathrm{~h}\end{array}$ & {$[0.14-0.86]$} & 0.35 \\
{$[0.08-0.4]$} & 0.19 \\
\hline $0.07-0.3]$ & 0.17 \\
\hline
\end{tabular}

- a significant decrease of the $\mathrm{TiB}_{2}$ powder particles size was recorded for the sample that was mechanically milled for 2 hours, which ensures a percentage decrease of $46 \%$ as compared to the initial sample, which was unmilled.

- the largest decrease of the $\mathrm{TiB}_{2}$ powder particles size is recorded for the sample that was 
mechanically milled for 3 hours, which ensures a percentage decrease of $53 \%$ as compared to the initial unmilled sample.

- there is a decrease of about $13 \%$ for the sample that was mechanically milled for 3 hours as compared to the sample that was mechanically milled for 2 hours, which leads to the conclusion that the latter case allowed for a smaller particle size distribution in comparison to the former one. As a general conclusion, it can be evinced that the milling regimes of the mechanical milling method proved to be very efficient, allowing the obtention of $\mathrm{TiB}_{2}$ nanometric powders in a very short milling time, up to 2 or 3 hours.

\section{ACKNOWLEDGEMENTS}

The authors are grateful to NATO Science for Peace and Security Multi-Annual Programme who has supported this research work through the NATO Grant SPS G5580, acronym ARMPROT.

\section{REFERENCES}

[1] Abdellahi M., Heidari J., Sabouhi R., Influence of B source materials on the synthesis of $\mathrm{TiB}_{2}-\mathrm{Al}_{2} \mathrm{O}_{3}$ nanocomposite powders by mechanical alloying, International Journal of Minerals, Metallurgy and Materials vol. 20, no 12, 2013, pp. 1214-1220.

[2] Demirskyi D., Agrawal D., Ragulya A., Tough ceramics by microwave sintering of nanocrystalline titanium diboride ceramics, Ceramics International, 40, 2014, pp. 1303-1310.

[3] Friedrich A., Winkler B., Juarez-Arellano E. A., Bayarjargal L., Synthesis of Binary Transition Metal Nitrides, Carbides and Borides from the Elements in the Laser-Heated Diamond Anvil Cell and Their Structure-Property Relations, Materials 4, 2011, pp. 1648-1692.

[4] Gomez I. V., Influence of nano-particles of alumina $\left(\mathrm{Al}_{2} \mathrm{O}_{3}\right)$ and titanium diboride $\left(\mathrm{TiB}_{2}\right)$ on the microstructure and properties of the alloy $\mathrm{Al}_{-} \mathrm{Cu}_{3}-\mathrm{Fe} 1-\mathrm{Si}_{9}$ for foundry applications to high pressure. Material chemistry. Université Sciences et TechnologiesBordeaux I, 2011

[5] Matveev A., Zhukov I., Ziatdinov M., Zhukov A., Planetary Milling and Self-Propagating High-Temperature Synthesis of Al-TiB ${ }_{2}$ Composites, Materials, 13, 2020, pp.1050.

[6] Moallem M., Abbasi M.H., Zadeh F.K., Synthesis and characterization of $\mathrm{TiB}_{2}$ nanocrystalline powder by mechanical alloying, International Journal of Modern Physics: Conference Series, Vol 5, 2012, pp. 204-211.

[7] Niyomwas S., Chaichana N., Memongkol N., Wannasin J., The effects of milling time on the synthesis of titanium diboride powder by self-propagating high temperature synthesis, Songklanakarin J. Sci. Technol. 30 (2), 2008, pp. 233-238.

[8] Tang W., Zheng Z., Wu Y., Wang J., Lu J., Liu J., Synthesis of $\mathrm{TiB}_{2}$ nanocrystalline powder by mechanical alloying, Transactions of Nonferrous Metal Society of China, 16, 2006, pp. 613-617.

[9] Xiang H., Feng Z., Li Z., Zhou Y., Temperature-dependence of structural and mechanical properties of $\mathrm{TiB}_{2}$ : A first principle investigation, Journal of Applied Physics 117, 2015, pp 225902. 